\title{
Correlation between hepcidin level and renal anemia
}

\author{
L.-N. Yang, P. Zhang, F. Tang, G. Wang and F.-E. Li \\ The Department of Nephrology, \\ 452nd Hospital of the Chinese People's Liberation Army, Chengdu, China \\ Corresponding author: F. Tang \\ E-mail: fengtang199@126.com
}

Genet. Mol. Res. 13 (3): 7407-7410 (2014)

Received June 24, 2013

Accepted May 27, 2014

Published September 12, 2014

DOI http://dx.doi.org/10.4238/2014.September.12.6

\begin{abstract}
Anemia in patients with chronic renal insufficiency (CRI) is related to the chronic inflammatory state, low iron absorption rate, and low utilization rate. As a key protein for iron metabolism, hepcidin plays an important role in CRI anemia. The study aimed to determine the correlation between hepcidin level and renal anemia. Ninety CRI anemia patients treated in our hospital from February 2012 to December 2012 were enrolled in the study to compare with a healthy control group of 40 cases by measuring the hepcidin level and analyzing the correlation between hepcidin level and CRI anemia. The hepcidin level was significantly higher in the CRI anemia group than the control group; there was a positive correlation between hepcidin level and serum ferritin as well as IL-6 level. Hepcidin level was significantly related to degree of anemia, indicating that an increase in hepcidin level will result in anemia.
\end{abstract}

Key words: Renal anemia; Hepcidin; Chronic renal insufficiency 


\section{INTRODUCTION}

Anemia in patients with chronic renal insufficiency (CRI) is related to the chronic inflammatory state, low iron absorption and utilization rate (Malyszko and Mysliwiec, 2007). Hepcidin, which was discovered in 2000 , is a modulator or iron homeostasis. It is a polypeptide of 25 amino acids, synthesized and secreted by hepatocytes. It can prevent the small intestine from absorbing ferritin and macrophages in reticuloendothelial system from releasing ferritin. As a result, anemia will occur (Krause et al., 2000; Nemeth and Ganz, 2006). There is little research on hepcidin levels in CRI anemia patents. This study investigated the relationship between hepcidin level and CRI anemia providing a clinical reference for treating renal anemia.

\section{MATERIAL AND METHODS}

Ninety CRI anemia patients treated in our hospital from February 2012 to December 2012 were enrolled as the patient group and 40 healthy cases as the control group. The CRI anemia group was divided into three groups based on degree of anemia: $>90 \mathrm{~g} / \mathrm{L}$ (Group A with 30 cases), 60-90 g/L(Group B with 30 cases) and $<60 \mathrm{~g} / \mathrm{L}$ (Group C with 30 cases). CRI anemia group had an average age of $44.8 \pm 18.4$ years old, and they had all received EPO or ferritin treatment without dialysis. The average age of the healthy group was $45.5 \pm$ 17.2 years old. They had no history of receiving EPO or ferritin treatment. The calculation of GFR was according to GFR evaluation formula issued by China eGFR Association: GFR $\mathrm{mL} \cdot \min ^{-1} \cdot\left(1.73 \mathrm{~m}^{2}\right)^{-1}=175 \mathrm{x}(\mathrm{Scr}, \mathrm{mg} / \mathrm{d} 1)^{-1.234} \mathrm{x} \mathrm{Age}^{-0.179} \mathrm{x}(0.79$ female $)$. The exclusion criteria were: acute infection (increased $\mathrm{C}$ reactive protein, $\mathrm{CRP}$ ), non-renal anemia, tumor history, chronic inflammatory reaction, hypoxic disease history.

\section{Serum hepcidin test}

A 3-mL venous blood sample was drawn during the morning before breakfast and put into an EDTA anticoagulant vacuum tube. After centrifugation for $10 \mathrm{~min}$ at $3000 \mathrm{rpm}$ at $4^{\circ} \mathrm{C}$, the blood serum was centrifuged and stored in a $-80^{\circ} \mathrm{C}$ freezer. The competitive ELISA with same phase was used to assay for hepcidin in blood serum. The kit (Human Hepcidin ELISA kit, S-1336) is produced by American Peninsula Laboratories (United Kingdom), and the assay was performed in accordance with instructions with the testable range of $0-25 \mu \mathrm{g} / \mathrm{L}$.

\section{Serum IL-6 test}

The IL-6 method was the same as for hepcidin. The kit (Human IL-6 ELISA kit, EK0410) is produced by Wuhan Boster.

\section{Other biochemical tests}

A fasting venous blood sample was drawn and sent to the clinical laboratory. Blood analyzer and automatic biochemical analyzer were used to perform routine blood tests, liver/ kidney function tests, CRP and blood fat test; a radioimmunoassay method was used to determine serum ferritin. 


\section{Statistical analysis}

SPSS 13.0 was adopted for statistical analysis. Normal variance homogeneity test was used for data that are reported as means $\pm \mathrm{SD}$, the $t$-test was adopted for the comparison between the average values of two sample groups, and the Tukey test was used for paired comparisons. One-way analysis of variance was adopted for the overall comparison between groups; Pearson's correlation analysis was used for the correlation between variables. In case of heterogeneity of variance, non-parameter tests were used. The Kruskal-Wallis test was adopted for multiple group comparison. The Mann-Whitney U test was used for paired comparison.

\section{RESULTS}

\section{Data of each group}

The data of each group are listed in Table 1. There was a significant difference in HB and in hepcidin between each group. Other variables did not differ between groups.

\begin{tabular}{|c|c|c|c|c|}
\hline \multirow[t]{2}{*}{ Items } & \multirow[t]{2}{*}{ Control group } & \multicolumn{3}{|c|}{ Patients group } \\
\hline & & Group A & Group B & Group C \\
\hline No. & 40 & 30 & 30 & 30 \\
\hline Age (years) & $40.43 \pm 12.21$ & $41.12 \pm 11.33$ & $40.98 \pm 12.32$ & $41.02 \pm 13.01$ \\
\hline BUN (mM) & $5.08 \pm 0.98$ & $21.32 \pm 4.53$ & $20.21 \pm 5.02$ & $19.94 \pm 5.22$ \\
\hline $\mathrm{Cr}(\mu \mathrm{M})$ & $69.33 \pm 20.32$ & $532.21 \pm 219.4$ & $527.98 \pm 208.76$ & $529.65 \pm 220.98$ \\
\hline GFR & $94.45 \pm 21.09$ & $26.25 \pm 7.09$ & $27.45 \pm 6.43$ & $26.42 \pm 6.31$ \\
\hline $\mathrm{HB}(\mathrm{g} / \mathrm{L})^{*}$ & $142.42 \pm 10.41$ & $109.35 \pm 7.42$ & $85.64 \pm 4.33$ & $73.63 \pm 8.32$ \\
\hline Red blood cell $\left(\times 10^{12} / \mathrm{L}\right)$ & $4.86 \pm 0.66$ & $3.67 \pm 0.58$ & $2.93 \pm 0.22$ & $2.21 \pm 0.42$ \\
\hline Platelet $\left(\times 10^{9} / \mathrm{L}\right)$ & $211.4 \pm 43.2$ & $172.2 \pm 66.4$ & $178.4 \pm 67.2$ & $174.3 \pm 70.2$ \\
\hline CPR (mg/L) & $1.55 \pm 0.49$ & $1.64 \pm 0.37$ & $1.55 \pm 0.44$ & $1.61 \pm 0.29$ \\
\hline IL-6 (ng/L) & $3.14 \pm 0.55$ & $5.19 \pm 0.81$ & $9.20 \pm 1.11$ & $14.87 \pm 3.41$ \\
\hline Hepcidin $(\mu \mathrm{g} / \mathrm{L})^{*}$ & $14.54 \pm 5.64$ & $30.22 \pm 13.5$ & $78.02 \pm 28.97$ & $114.32 \pm 33.7$ \\
\hline
\end{tabular}

$* \mathrm{P}<0.05 . \mathrm{BUN}=$ blood urea nitrogen; $\mathrm{Cr}=$ creatine; GFR = glomerular filtration rate; HB = hemoglobin; IL-6 = interleukin-6.

\section{Correlation analysis on serum hepcidin level and other biochemical variables}

There was a positive correlation between hepcidin level and serum HB, RBC, and GFR, as well as IL-6 in each group as indicated in Table 2.

\begin{tabular}{lcc}
\multicolumn{2}{c}{ Table 2. Correlation between hepcidin and biochemical indexes. } & P \\
\hline & $r$ value & 0.014 \\
GRF & 0.664 & 0.032 \\
HB & 0.732 & 0.013 \\
RBC & 0.703 & 0.022 \\
IL-6 & 0.644 & 0.345 \\
CRP & 0.632 & \\
\hline RBC $=$ red blood cells; CRP = C-reactive protein. For other abbreviations, see legend to Table 1.
\end{tabular}

$\mathrm{RBC}=$ red blood cells; CRP $=\mathrm{C}$-reactive protein. For other abbreviations, see legend to Table 1.

\section{DISCUSSION}

Rats with hepcidin gene-knockout show iron overload (Lesbordes-Brion et al., 2006). 
Rats with hepcidin gene over-expression and people with high hepcidin level suffer hypoferric anemia (Weinstein et al., 2002; Swinkels and Wetzels, 2008). Investigators have paid attention to the relationship between CRI hepcidin and anemia and inflammatory reaction, as well as hypoxia.

In this study, there was negative correlation between hepcidin level and degree of anemia. The variances of paired comparison between the 3 groups of CRI patients and healthy groups were statistically significant. There was a negative correlation between hepcidin level and GFR, which indicates that renal damage gets worse with increase in hepcidin level. There was a positive correlation between hepcidin and IL-6 levels. The differences in hepcidin between CRI anemia groups and healthy group showed statistical significance, which indicates that CRI patients' slight inflammatory reaction stimulates the increase in hepcidin and further affects iron metabolism to result in anemia. There was a positive correlation between hepcidin and ferritin, which is a marker that indicates iron storage in the human body. It has been demonstrated that an increased hepcidin level can prevent macrophages in the reticuloendothelial system from releasing ferritin, resulting in hypoferric anemia.

As in-depth research proceeds, it is expected that hepcidin will be used as an effective drug for treating iron overload disease such as hereditary hemochromatosis and Alzheimer disease, as well as iron insufficiency disease such as inflammatory reaction and anemia of chronic disease.

\section{REFERENCES}

Krause A, Neitz S, Magert HJ, Schulz A, et al. (2000). LEAP-1, a novel highly disulfide-bonded human peptide, exhibits antimicrobial activity. FEBS Lett. 480: 147-150.

Lesbordes-Brion JC, Viatte L, Bennoun M, Lou DQ, et al. (2006). Targeted disruption of the hepcidin 1 gene results in severe hemochromatosis. Blood 108: 1402-1405.

Malyszko J and Mysliwiec M (2007). Hepcidin in anemia and inflammation in chronic kidney disease. Kidney Blood Press Res. 30: 15-30.

Nemeth E and Ganz T (2006). Regulation of iron metabolism by hepcidin. Annu. Rev. Nutr. 26: 323-342.

Swinkels DW and Wetzels JF (2008). Hepcidin: a new tool in the management of anaemia in patients with chronic kidney disease? Nephrol. Dial. Transplant. 23: 2450-2453.

Weinstein DA, Roy CN, Fleming MD, Loda MF, et al. (2002). Inappropriate expression of hepcidin is associated with iron refractory anemia: implications for the anemia of chronic disease. Blood 100: 3776-3781. 